\title{
A retomada da Educação Profissional - O caso da Formulação do Pronatec
}

Fabiana Carvalho da Silva Bispo Universidade de Brasilia, Brasil

\section{Resumo}

A retomada da Política de Educação Profissional ocorreu em um contexto de recuperação do crescimento econômico do país onde se demandavam crescentes volumes de mão de obra especializada em contraste com um baixo nível de qualificação de parcela majoritária dos trabalhadores brasileiros. Assim, foi instituído, a partir da Lei n. 12.513, de 26 de outubro de 2011, o Programa de Acesso ao Ensino Técnico e Emprego, o Pronatec, com o objetivo democratizar a oferta de cursos de educação profissional e tecnológica por meio de um conjunto de ações aumentando a produtividade e a competitividade do país, com inclusão social. O artigo se propõe assim a fazer uma reflexão sobre o processo de formulação do programa no contexto das mudanças que vêm ocorrendo na política educacional do país quanto à educação profissional.

Palavras-chave: Educação Profissional, Pronatec, Política Educacional. 


\section{Abstract}

The resumption of the Professional Education Policy took place in a context of recovery of the economic growth of the country where increasing volumes of skilled labor demanded in contrast to a low level of qualification of the majority share of Brazilian workers. Thus, it was established, from Law no. 12,513 of October 26, 2011, the Pronatec Program of Access to Technical Education and Employment, aiming to democratize the offer of vocational and technological education courses based on a set of actions increasing the productivity and competitiveness of the country, with social inclusion. The article thus proposes to reflect on the process of formulating the program in the context of changes that have been taking place in the educational policy of the country regarding professional education.

Keywords: Professional Ed ucation, Pronatec, Educational policy.

\section{Resumen}

La retomada de la Política de Educación Profesional ocurrió en un contexto de recuperación del crecimiento económico del país donde se demandaban crecientes volúmenes de mano de obra especializada en contraste con un bajo nivel de calificación de parcela mayoritaria de los trabajadores brasileños. Así, se estableció, a partir de la Ley n. 12.513, de 26 de octubre de 2011, el Programa de Acceso a la Enseñanza Técnica y Empleo, el Pronatec, con el objetivo de democratizar la oferta de cursos de educación profesional y tecnológica a partir de un conjunto de acciones aumentando la productividad y la competitividad del país, con inclusión social. El artículo se propone así hacer una reflexión sobre el proceso de formulación del programa em el contexto de los cambios que vienen ocurriendo en la política educativa del país en cuanto a la educación profesional.

Palabras clave: Educación Profesional, Pronatec, Politica Educativa. 


\section{Resumé}

La reprise de la politique de formation professionnelle a eu lieu dans un contexte de reprise de la croissance économique du pays où des volumes croissants de main-d'œuvre qualifiée ont exigé, contrairement à un faible niveau de qualification de la part majoritaire des travailleurs brésiliens. Ainsi, il a été établi, à partir de la loi no. 12513 du 26 octobre 2011, le Programme Pronatec d'Accès à l'Enseignement Technique et à l'Emploi, visant à démocratiser l'offre de cours d'enseignement professionnel et technologique sur la base d'un ensemble d'actions augmentant la productivité et la compétitivité du pays, avec inclusion sociale. L'article propose donc de réfléchir sur le processus de formulation du programme dans le conteste des changements qui ont eu lieu dans la politique éducative du pays en matière de formation professionnelle.

Mots-clés: Enseignement professionnel, Pronatec, Politique éducative. 


\section{Introdução}

Falar sobre a importância da educação para o desenvolvimento de uma nação não é novidade. Adam Smith, filósofo e renomado economista escocês do século XVIII, incluía a educação como parte do capital fixo, consistindo nas aptidões e habilitações dos membros de uma sociedade que, quando desenvolvidas, fazem reverter a ela seus benefícios. Durkheim, citado por Fauconnet (1978), define educação como o desenvolvimento do indivíduo nas atitudes e capacidades que lhes são exigidas não apenas pela sociedade em geral, como também pelo meio especial a que, em particular, está determinado. A educação é, deste modo, um importante fator na formação de um indivíduo.

Ao longo do tempo, a necessidade de formação de um novo tipo de trabalhador, requerida pelo novo padrão de desenvolvimento mundial e nacional, passaram a exigir mudanças nos papéis sociais da educação e, consequentemente, na natureza e organização do sistema educacional brasileiro. Um vasto conjunto de leis, decretos, resoluções e pareceres, ao lado de uma série de ações e programas governamentais, passaram a regular e coordenar a execução das políticas públicas para a educação profissional e tecnológica.

Contudo, várias destas ações e destes planos voltados para a área profissional foram elaborados e malsucedidos, revelando uma ausência de políticas públicas consistentes de Educação Profissional. A reforma do ensino médio e profissional durante o governo Fernando Henrique Cardoso (19952002) desencadeou mudanças estruturais, provocando a entrada de novos protagonistas, como: sindicatos, associações comunitárias, organizações não governamentais, bem como redefinindo responsabilidades no campo 
da gestão e do financiamento da educação profissional e tecnológica. A desarticulação e a fragmentação das iniciativas governamentais em vários programas e projetos induziam a sobreposições de oferta e a um modelo de financiamento fragmentado, sem critérios comuns de custo-aluno e, portanto, mais elevado (Kuenzer, 2010).

Com a retomada do crescimento econômico, novas demandas da parte do empresariado por investimentos na formação e capacitação profissional de pessoas começaram a surgir, o que gerava uma expectativa de preenchimento de novas vagas, em todas as regiões do país. Todo esse contexto criou um "humor nacional" propício ao novo projeto do governo federal. Assim, no início de 2011, foi encaminhado ao Congresso Nacional, pela presidenta Dilma Rousseff, um projeto de lei que criaria o Programa Nacional de Acesso ao Ensino Técnico em Emprego, conhecido como Pronatec. Os cursos de formação profissional, oferecidos pelo programa, foram vistos como uma alternativa viável e que atendia tanto aos anseios do empresariado quanto de sindicatos e da população em geral.

Considerando que a formulação de uma política pública é um processo de mudança complexo onde as decisões do governo são transformadas em programas, procedimentos, regulamentos ou práticas que visem à melhoria social, práticas de gestão ineficazes podem fracassar ou tornar inexequível a implementação de boas políticas públicas. Estudos técnicos realizados à época do lançamento do Pronatec revelaram que a proposta do programa foi bem acolhida e tornou-se a "vitrine" do mandato da Presidente Dilma Rousseff, o que gerou vários rumores sobre a formulação do programa levando a reflexões sobre as articulações pelas quais passou e o clima que experimentou (CNTE, 2011; Gomes, 2016; Lima, 2012). 
O artigo se propõe, assim, a fazer uma reflexão sobre o processo de formulação do Programa no contexto das mudanças que vêm ocorrendo na política educacional do país quanto à educação profissional. Para tanto, primeiramente, faz-se uma análise do papel social do Estado, passando para um breve panorama na educação profissional no Brasil e seguindo para uma abordagem do Pronatec, objeto de estudo deste artigo. A metodologia da pesquisa baseou-se em levantamento bibliográfico sobre abordagens sobre educação, especificamente, educação profissional e tecnológica presentes na literatura nacional e internacional das áreas de educação e políticas públicas.

\section{A Função Social do Estado}

Dentro da ótica do "bem-estar social", o Estado, enquanto provedor, deverá satisfazer as necessidades da coletividade. Por meio de planos, programas, políticas e ações diversas, o Estado visa atender aos anseios da população. A função social do Estado inclui os serviços públicos, a segurança pública e o bem-estar de todos. Isto exige políticas específicas destinadas a todos os setores mais vulneráveis da população. Acredita-se que a função social do Estado contribui também para a melhor distribuição de renda na população. De acordo com a Constituição Federal do Brasil de 1988, em seu artigo $3^{\circ}$, inciso III, um dos objetivos fundamentais da República Federativa do Brasil é erradicar a pobreza e a marginalização e reduzir as desigualdades sociais e regionais.

Estudos sobre a pobreza consideram que o Estado é central para a redução da pobreza e a criação de melhores condições para a inclusão social e a equidade. A equidade é medida comparando-se os níveis de renda, acesso 
a serviços, propriedade dos bens de produção e participação na sociedade e no processo decisório dos diferentes grupos em uma sociedade. Segundo Rawls (1997), o tratamento desigual é justo quando é benéfico ao indivíduo mais carente sob o critério de justiça na desigualdade. Portanto, promover a equidade é promover as condições para que todos tenham acesso ao exercício de seus direitos civis (liberdade de expressão, de acesso à informação, de associação, de voto, igualdade entre gêneros), políticos e sociais (saúde, educação, moradia, segurança).

Gramsci (2000) considerava que nas sociedades ocidentais, o Estado, em sentido amplo, o Estado ampliado, a superestrutura, é a junção de duas esferas, a sociedade política e a sociedade civil. A sociedade política seria o Estado em sentido estrito (Estado-coerção), formada pelo conjunto dos mecanismos através dos quais a classe dominante detém o monopólio legal da repressão e da violência e se identifica com os aparelhos coercitivos ou repressivos de Estado, controlados pelas burocracias. A sociedade civil (Estado ético), composta por organizações responsáveis pela elaboração e/ou difusão das ideologias, compreenderia as escolas, as igrejas, os partidos políticos, os sindicatos, as organizações profissionais, os meios de comunicação etc.

No âmbito e por meio da sociedade civil, as classes buscam exercer sua hegemonia. A sociedade é assim vista como uma organização constituída de instituições complexas, públicas e privadas, articuladas entre si, cujo papel histórico varia através das lutas e relações de grupos específicos e poderes, que se articulam pela busca da garantia da hegemonia dos seus interesses. É no âmbito da reflexão do Estado ampliado que Gramsci questiona as liberdades civis e políticas do Estado democrático, nesta visão, a formulação de uma proposta para a educação que integre um programa político em 
direção à igualdade social é referência para a crítica às desigualdades produzidas pelo sistema capitalista.

Ciavatta (2002) considera que quando se fala no período pós-militar, do ponto de vista da sociedade mais ampla e de suas instituições, frequentemente se reduz o processo à inibição da ação dos aparelhos de coerção do Estado ( em sentido restrito), identificando como um governo historicamente centralizador, repressivo e comprometido com interesses alheios às demandas vitais de sobrevivência da população.

Na visão de Rua (2000), desde a década de 1930, o Estado assumiu uma função central na economia, seja através do ingresso direto na atividade econômica, como produtor, seja como promotor direto do desenvolvimento, segundo o modelo de substituição das importações. Assumiu também, em proporções menores, funções sociais, com a política de proteção ao trabalho, através da Consolidação das Leis Trabalhistas (CLT) e, mais tarde, com algumas políticas de saúde e de educação pública, ou até mesmo de habitação.

Entretanto, segundo essa mesma autora, durante a maior parte do tempo, a maioria das políticas sociais brasileiras esteve restrita aos que possuíam empregos formais, descaracterizando a dimensão universalista típica do Estado de Bem-Estar. Somente com a Constituição Federal do Brasil de 1988, e em algumas áreas específicas, como a de educação e de saúde, é que foram efetivamente implementadas políticas sociais universalistas. Para Ciavatta (2002), essa visão unilateral obscurece a compreensão do estado em sentido ampliado e a existência das forças sociais em presença, que por sua vez, pressionaram a abertura do processo de redemocratização do país, reivindicando a satisfação de suas necessidades básicas. 
Segundo Oliveira (2009), nas duas últimas décadas, dado, dentre outros fatores, os altos níveis de desigualdade dos países latino-americanos em geral, e especialmente o Brasil, têm-se vivido uma onda de reformas no Estado que trouxe um novo desenho para as políticas educacionais. Giddens (2000) argumenta que a necessidade de melhores qualificações educacionais e de treinamento em habilidades, principalmente no que se refere aos mais necessitados, é evidente na maioria dos países industrializados, tornando-se um imperativo de governo na redistribuição de possibilidades. Ciavatta (2002) destaca três movimentos principais que refletem as diferentes conjunturas históricas das políticas educacionais, a saber: as políticas e planos educacionais que expressam a intenção de abranger as questões educacionais como um todo; as políticas que caracterizam por um projeto de educação com ênfase na preparação da força de trabalho; e as políticas mais fragmentárias. Neste aspecto, destacase o papel da educação profissional e tecnológica no Brasil.

\section{A Educação Profissional e Tecnológica no Brasil - um breve panorama}

Para se falar sobre a formação para o trabalho, atualmente conhecida como educação profissional, faz-se necessária uma abordagem do seu contexto histórico. Em linhas gerais, a economia colonial brasileira, fundada na grande propriedade e na mão-de-obra escrava, teve implicações de ordem social e política bastante profundas, favorecendo o aparecimento da unidade básica do sistema de produção, de vida social e do sistema de poder representado pela família patriarcal. 
Com a apropriação privada da terra, os homens se dividiram em classes: a classe dos proprietários e a dos não-proprietários, gerando uma divisão na educação. Essa que antes se identificava com o próprio processo de trabalho, assume um caráter dual, constituindo-se em educação para os homens livres pautada nas atividades intelectuais, enquanto que para os serviçais e escravos coube a educação inerente ao próprio processo de trabalho. Assim, ao mesmo tempo em que se ofereceu à camada dominante a oportunidade de crescimento intelectual, a educação se manteve precária nos demais níveis, atingindo apenas uma minoria que nela procurava uma forma de conquistar ou manter status. Poucas foram as políticas que alcançaram êxito para a efetivação da formação do trabalhador. A escassez de boas políticas e o desinteresse do Estado revelam a despreocupação em preparar (educar) o trabalhador para o ofício (Romanelli, 2005; Savianni, 2007; Gomes, 2013).

Gomes (2004) considera que o descaso com o ensino profissional foi fruto de inúmeras propostas e reformas malsucedidas provenientes de disputas entre classes que sempre existiram no país. Para Romanelli (2005), a função da escola sempre esteve associada à manutenção de privilégios de classes e para isso, utilizaram-se mecanismos de seleção escolar e um conteúdo cultural que não foram capazes de propiciar às diversas camadas sociais uma preparação democrática adequada para os trabalhadores. Segundo esta autora, como o contexto histórico-social apontava para a produção e para a exportação de produtos primários, não havia necessidade de mãode-obra mais qualificada. Nas cidades, o trabalho era realizado por profissionais de ofícios urbanos, que aprendiam o ofício no exercício da própria atividade. 
No início do século XIX, com a transferência da corte portuguesa para o Brasil e a consequente revogação do referido Alvará, D. João VI cria, em 1809, o Colégio das Fábricas, considerado o primeiro estabelecimento instalado pelo poder público destinado à educação profissional no Brasil. Em 1816, cria-se a Escola de Belas Artes com o objetivo de articular o ensino das ciências e do desenho para os ofícios a serem realizados nas oficinas mecânicas (Moura, 2010).

Em 1840, foram criadas as escolas de ofício, mantidas pelo Estado e destinadas a ensinar trabalhos manuais e artesanais a órfãos que viviam da produção das próprias escolas. Essas instituições tinham propostas direcionadas para o ensino das primeiras letras e a iniciação aos ofícios como a tipografia, a carpintaria, a sapataria, a tornearia, dentre outras. Com o advento da Revolução Industrial, o ensino básico era visto como uma forma de qualificar os trabalhadores a integrar o processo produtivo. Quanto às tarefas de manutenção, reparos, ajustes das máquinas que, por sua vez, exigiam, além do conhecimento teórico, um preparo específico, fizeram surgir os cursos profissionais organizados no âmbito das empresas ou do sistema de ensino tendo como referência o padrão escolar.

Dessa forma, a educação profissional foi vista como instrumento de capacitação para atender ao crescente desenvolvimento industrial e ao ciclo de urbanização, com um caráter assistencialista em relação à classe trabalhadora. Foram criadas ainda instituições destinadas a acolher crianças órfãs e abandonadas, possibilitando-lhes uma base de instrução teórica e prática e iniciando-as no ensino industrial. As mais importantes foram os Liceus de Artes e Ofícios do Rio de Janeiro (1858), de Salvador (1872), do Recife (1880), de São Paulo (1882), de Maceió (1884) e de Ouro Preto (1886) (Romanelli, 2005; Gomes, 2013; Moura, 2010). 
Nas primeiras décadas do século XX, O processo de industrialização aumentou a oferta de trabalho e houve migração de trabalhadores da zona rural para as cidades. Como a maioria dos trabalhadores não possuíam formação específica, o Governo recorreu à institucionalização de agências profissionalizantes, paralelas ao sistema oficial, a fim de qualificar a mão-deobra para os dois principais pilares da economia: a Indústria e o Comércio.

Assim, foi sancionado pelo então Presidente da República Nilo Peçanha, o Decreto-Lei $n^{\circ}$ 7.566, de 23 de setembro de 1909, que instituiu oficialmente a educação profissional brasileira, resultando, dentre outros, na criação de dezenove Escolas de Aprendizes Artífices, visando preparar gerações futuras para a continuidade dos ofícios, atendendo, deste modo, a demanda do mercado produtivo, então dominado pela burguesia emergente, qualificando profissionais advindos das camadas inferiores da população.

Ciavatta (2002) destaca que nos anos 30 do século passado, no Governo Getúlio Vargas, a expansão capitalista e da industrialização retoma o encaminhamento de solução da questão social através da legislação sindical e trabalhista, do amparo social do trabalhador e da criação das escolas agrárias e técnico-industriais. Esta autora destaca ainda que a Constituição de 1937 assegurava, na forma da lei, em seu artigo 129, que o ensino pré-vocacional e profissional destinado às classes menos favorecidas é o primeiro dever do Estado, em se tratando de educação.

Na década de 40 desse mesmo século, foram criadas as instituições responsáveis pela formação de mão-de-obra para os dois principais pilares da economia: a Indústria e o Comércio, conhecido como sistema S. Este momento assinala uma mudança na concepção da função social da educação, ou seja, o sistema paralelo de ensino profissional destinado aos 
desfavorecidos já não atendia mais às novas necessidades, a saber, a industrialização (Wittaczik, 2008; Ciavatta, 2002).

O governo de Juscelino Kubitschek aprofunda a relação entre Estado e economia. O Plano de Metas previa investimentos maciços nas áreas de infraestrutura e, dentre outros aspectos, objetivava a formação de profissionais orientados para as metas de desenvolvimento do país. No ano de 1959, as Escolas Industriais e Técnicas são transformadas em autarquias com o nome de Escolas Técnicas Federais (Wittaczik, 2008; Ciavatta, 2002).

O termo "educação tecnológica" começou a ser usado no início de 1970, com a criação dos cursos superiores de tecnologia implantados pelo Centro Estadual de Educação Tecnológica Paula Souza, do estado de São Paulo (CEETPS) e, a partir de 1972, foram expandidos, posteriormente, para todo o país pelo Governo Federal. Foram criados, em 1976, o Centro de Educação Tecnológica da Bahia (CENTEC/BA) e, em 1978, os Centros Federais de Educação Tecnológica do Paraná, Minas Gerais e Rio de Janeiro, que aproveitando a infraestrutura existente das antigas escolas técnicas federais, passaram a incluir outros níveis de formação na área tecnológica.

Em 1994, a Lei $n^{\circ}$ 8.948, de 8 de dezembro, dispõe sobre a instituição do Sistema Nacional de Educação Tecnológica, transformando, gradativamente, as Escolas Técnicas Federais e as Escolas Agrotécnicas Federais em Centros Federais de Educação Tecnológica - CEFETs (WITTACZIK, 2008; Ciavatta, 2002).

Conforme destaca Wittaczik (2008), ao longo do tempo, várias foram as expressões referentes à educação profissional, tais como ensino profissional, formação profissional ou técnico profissional, educação industrial ou técnico- 
industrial, qualificação, requalificação e capacitação, sem, contudo, obter consenso sobre o significado desses termos.

O termo educação profissional foi introduzido pela Lei de Diretrizes e Bases da Educação - LDB (Lei n 9.394/96, cap. III, art.39): "A educação profissional, integrada às diferentes formas de educação, ao trabalho, à ciência e à tecnologia, conduz ao permanente desenvolvimento de aptidões para a vida produtiva." Segundo Cordão (2006), o novo enfoque dado à educação profissional supõe a superação total do entendimento tradicional de educação profissional como simples instrumento de uma política de cunho assistencialista, ou mesmo como linear ajustamento às demandas do mercado de trabalho. Desta forma, segundo este autor, a educação profissional é considerada como uma importante estratégia para que os cidadãos, em número cada vez maior, tenham efetivo acesso às conquistas científicas e tecnológicas da sociedade contemporânea.

A criação do PLANFOR (Plano Nacional de qualificação do Trabalhador), em 1995, lançou as bases para se atingir a estabilidade econômica, buscando elevar a produtividade do trabalho, incluindo a educação profissional na política pública de trabalho. O PROEP (Programa de Expansão da Educação Profissional) teve seu marco inicial em 1997, com o objetivo de desenvolver ações integradoras da educação e do trabalho, a ciência e a tecnologia, visando à implantação de um novo modelo de educação profissional que proporcionasse a ampliação de vagas, a diversidade de oferta e a definição de cursos adequados às demandas do mundo do trabalho (Wittaczik, 2008; Ciavatta, 2002).

Na década de 90, deu-se também a Criação do Sistema Nacional de Educação Tecnológica, sistema formado pelos CEFETs. Contudo, em 1998, o Governo Federal veta a criação de novos CEFETs, resultando, dentre outros 
aspectos, na separação do ensino médio da educação técnica e os CEFETs se voltam para a educação superior (Wittaczik, 2008; Ciavatta, 2002).

\section{A Retomada da Educação Profissional}

O discurso hegemônico do governo defendia que a educação profissional era o caminho para o desenvolvimento social e econômico do país. O tratamento a ser dado à educação profissional, anunciado pelo Ministério da Educação (MEC) no início do Governo Lula, seria de reconstruí-la como política pública e corrigir distorções de conceitos e de práticas decorrentes de medidas adotadas pelo governo anterior.

Assim, no ano de 2003, foi iniciada uma expansão da rede federal de educação profissional. Em 2005, o veto à criação de novos CEFETs foi derrubado e criou-se, por meio da Lei n 11 1.892/2008, no âmbito do Ministério da Educação, um novo modelo de instituição de educação profissional e tecnológica, os Institutos Federais de Educação, Ciência e Tecnologia (IFTs). A Lei 11.892/08 integrou um conjunto de medidas normativas que visava à concretização do Plano de Desenvolvimento da Educação (PDE) do governo Lula, que o tinha como um dos mais importantes componentes educacionais do Plano de Aceleração do Crescimento (PAC).

O Programa de Integração da Educação Profissional ao Ensino Médio na Modalidade de Educação de Jovens e Adultos (PROEJA), cujo objetivo é a ampliação dos espaços públicos da educação profissional para os adultos e a contribuição para a universalização da educação básica, obrigava as instituições da rede federal de educação técnica e tecnológica a destinar, em 2006, o correspondente a 10\% das vagas oferecidas em 2005 para o 
ensino médio integrado à educação profissional destinado a jovens acima de 18 anos e adultos que tenham cursado apenas o ensino fundamental.

Tem-se, ainda, o Programa Nacional de Inclusão de Jovens (PROJOVEM) implantado pela Secretaria-Geral da Presidência da República em parceria com o Ministério da Educação, o Ministério do Trabalho e Emprego e o Ministério do Desenvolvimento Social e Combate à Fome, cujos destinatários são jovens na faixa de 18 a 24 anos de idade que terminaram a quarta série, mas não concluíram a oitava série do ensino fundamental e não têm vínculos formais de trabalho.

O programa Brasil Profissionalizado, datado de 2007, integra o PDE da mesma forma que outras iniciativas voltadas à educação profissional e vem financiar a ampliação e o equipamento das redes estaduais de ensino médio, adequando mais escolas estaduais para ampliar a oferta de ensino médio integrado à educação profissional. O programa visa repassar recursos para os estados a fim de incentivá-los a retomar o oferecimento da educação profissional gratuita de nível médio na rede de educação pública estadual.

Em 2008, é estabelecido o Acordo de Gratuidade com o Sistema S, com o compromisso de chegar à aplicação de dois terços de suas receitas líquidas na oferta de vagas gratuitas nos cursos de formação para estudantes com renda familiar de até 1,5 salários-mínimos, trabalhadores empregados ou desempregados.

Atualmente, a educação profissional, segundo disposto na Lei $n^{\circ} 11.741$, de 2008, se organiza nos seguintes cursos: I - de formação inicial e continuada ou qualificação profissional; II - de educação profissional técnica de nível médio, que pode ser subsequente ao ensino médio (para quem já concluiu a educação básica); concomitante ao ensino médio (para quem já concluiu o ensino fundamental e está cursando o ensino médio); integrada ao ensino 
médio (em currículo único com esta etapa da educação básica), inclusive na modalidade EJA; III - de educação profissional tecnológica de graduação e pós-graduação.

Acrescentam-se ainda: Programa Mulheres-mil; Programa de Expansão da Rede Federal de Educação Profissional; Rede E-Tec Brasil; Curso Técnico de Formação para os Funcionários da Educação (Profuncionário) e o Programa Nacional de Acesso ao Ensino Técnico e Emprego (Pronatec).

\subsection{Visões críticas}

Frigotto et al (2005) relatam que, apesar da produção de conhecimentos sobre contradições, desafios e possibilidades da educação profissional produzidas especialmente no âmbito da área Trabalho e Educação, a realidade mostrou um percurso controvertido entre as lutas da sociedade, as propostas de governo e as ações e omissões no exercício do poder.

Segundo Neves (2000), além das metas quantitativas quanto à escolarização brasileira do século XXI, a proposta do Plano Nacional de Educação (PNE) do governo tinha como meta implantar, em consonância com o Decreto 2.208/97, e em até cinco anos, a reforma do Ensino Médio e da Educação Profissional, à revelia dos interesses da sociedade, implicando na transformação, gradativa, de unidades de educação técnica federal em Centros Públicos de Educação Profissional.

De acordo com a autora, isso implicaria em mobilizar, articular e ampliar a capacidade instalada na rede de instituições de educação profissional de modo a triplicar, a cada cinco anos, a oferta de educação profissional 
permanente para a população que precisava se adaptar às novas exigências e perspectivas do mercado de trabalho. Uma proposta de formação, na visão de Neves (2000), organicamente desenvolvida.

Para Otranto (2012), nessa expansão da educação profissional havia dois interesses, a saber: os interesses do setor empresarial e os do setor educacional. Na visão da autora, o setor empresarial tem como referência as finalidades produtivas, enquanto ao setor educacional cabe formar para o exercício da cidadania que envolve a aquisição dos meios indispensáveis a uma vida mais digna, respeitando os valores sociais e os direitos e deveres dos cidadãos. Dessa forma, a lógica capitalista, que é a lógica da produção, difere da lógica da educação, voltada para a formação do indivíduo, e assim sendo, o conflito estaria armado.

Segundo Boito Jr (2008), a política econômica da era Lula configurava uma trajetória de melhoria da posição ocupada pelos interesses da grande burguesia interna em detrimento dos interesses da burguesia compradora e do capital financeiro internacional e a priorização dos interesses dos empresários pelo Estado brasileiro aparece em inúmeros aspectos da política dos governos Lula e, posteriormente, no Governo Dilma. Frigotto et al (2005) ressaltam que a problematização sobre a política de educação profissional, que tem como referência a produção de conhecimento na área e as lutas sociais, revelou um percurso tomado por essa política que representou, na verdade, a disputa entre os setores progressistas e conservadores da sociedade brasileira pela hegemonia nesse campo.

Cassiolato e Garcia (2014), numa visão mais positiva, destacam que o crescimento da rede de ensino técnico-profissional não acompanhou a expansão econômica e a diversificação da estrutura produtiva, o que resultou em uma baixa escolaridade da força de trabalho. Considerando, 
assim, o déficit educacional verificado, logo no primeiro ano do atual governo houve um esforço articulado do Ministério da Educação para a elaboração de uma ampla política de fomento à Educação Profissional e Tecnológica idealizada no governo anterior, considerada primordial para o desenvolvimento do país. O governo apresenta, assim, o ensino técnico como o caminho de oportunidade para o desenvolvimento econômico do país e para a superação das desigualdades e essencial na atividade produtiva do país.

Na visão de Gramsci (2000), o exercício da hegemonia estaria situado como uma relação pedagógica que busca subordinar, em termos morais e intelectuais, diferentes grupos sociais por meio da persuasão e da educação. Neves (2010) argumenta que uma educação para o consenso é a que busca garantir a coesão social nos moldes de uma nova sociabilidade na qual os sentidos de democracia, cidadania, ética e participação, por exemplo, são redefinidos de acordo com os interesses privados do capital nacional e internacional. Nesta linha de pensamento, o discurso governamental para a retomada da educação profissional demonstra a construção do consenso e da legitimação da estratégia do governo de formação da classe trabalhadora, porém com forte presença do setor privado e do capital nacional e internacional.

Após ter passado por reformas estruturais no final do século passado, o Brasil pôde desfrutar de desenvolvimento econômico considerável. Como ressaltaram Cassiolato e Garcia (2014), o mercado de trabalho nacional experimentou considerável ampliação de postos e de formalização dos contratos de trabalho. Entretanto, como consequência, os primeiros sinais pontuais de escassez de mão de obra especializada passaram a aparecer entre 2006 e 2007. Considerando, assim, o déficit educacional verificado, 
logo no primeiro ano do governo Dilma houve um esforço articulado do Ministério da Educação para a elaboração de uma ampla política de fomento à Educação Profissional e Tecnológica, idealizada no governo anterior, considerada primordial para o desenvolvimento do país.

O lançamento do Programa Nacional de Acesso ao Ensino Técnico e Emprego, o Pronatec, no ano de 2011, adveio da ideia de estimular a articulação entre a política de educação profissional e tecnológica e as políticas de geração de trabalho, tendo como objetivo principal democratizar o acesso da população brasileira à Educação Profissional e Tecnológica (EPT) de qualidade. Para muitos, o Pronatec representa mais um atendimento à demanda empresarial com recursos destinados a formar um profissional especializado para aumentar o lucro das empresas do que necessariamente um programa voltado para atendimento das necessidades de uma parcela da população.

\section{O Programa Nacional de Acesso ao Ensino Técnico e Emprego (Pronatec)}

\subsection{Formulação do Programa}

A expressão "formulação de políticas públicas" engloba todo o processo de discussão, aprovação e implementação de uma política pública. Constituise, em muitos casos, em um estágio em que os governos democráticos transformam seus propósitos e suas plataformas eleitorais em ações e programas que produzem resultados ou mudanças concretas no mundo real (Allison, Graham; Zelikow, 1999; Kingdon, 2011; Sabatier, 2007).

Um problema é considerado como uma discrepância entre a situação social percebida e a desejada e para o qual alternativas serão formuladas a fim de 
solucioná-lo integralmente ou mitigá-lo. Frequentemente, os governos são confrontados com situações de escolha forçada, onde eles simplesmente não podem ignorar o sentimento público sem arriscar a perda de legitimidade ou credibilidade, e devem dar ao problema em questão alguma prioridade na agenda. Assim, dado o grande volume de decisões e a incapacidade de lidar de maneira plena com todas as questões ao mesmo tempo, a atenção dos formuladores de políticas públicas depende da forma como eles as percebem e as interpretam e da forma como são definidas como problemas. De tal modo, concentram sua atenção em algumas questões e ignoram outras (Fischer; Miller; Sidney, 2007; Gelinski; Seibel, 2008; Kingdon, 2011).

O estudo da definição da agenda nos permite entender como são interpretados, pelo governo, os problemas fundamentais do Estado. A agenda governamental é definida como o conjunto de assuntos sobre os quais o governo e as pessoas a ele ligadas concentram sua atenção em um determinado momento. Buscando compreender por que um determinado assunto passa a chamar a atenção dos formuladores de políticas públicas e ascende à agenda e por qual motivo alguns temas podem ser descartados, focando sua análise no governo federal norte americano, caracterizando-o como "anarquia organizada", Kingdon (2011) concluiu que o processo de formulação da agenda é um processo altamente competitivo e que mudanças na agenda ocorrem quando da convergência de três grandes fluxos: o fluxo dos problemas (problems), o fluxo das propostas ou alternativas (policies) e o fluxo da política (politics). Esses fluxos fluem em grande parte independentes uns dos outros até que as circunstâncias levem a uma convergência, resultando em políticas públicas. 
Quando um problema entra na agenda governamental, alternativas são formuladas e o comportamento dos atores no jogo do poder ocorre de diferentes formas e cabe ao governo fixar prioridades, metas e objetivos a serem alcançados. Um item pode estar presente na agenda governamental, sem necessariamente ser matéria de decisão. Por sua vez, a passagem para determinada instância decisória não garante a sua implementação, conforme a intenção original do poder em questão. Embora vários atores estejam envolvidos nas atividades de controle ou modelagem da agenda, a maioria das variáveis e dos mecanismos que afetam o estabelecimento de agendas está fora do controle direto de qualquer ator individual (Kingdon, 2011).

Também influenciam a agenda os indivíduos nomeados pelo presidente nos altos escalões da burocracia governamental, como ministros e secretários de Estado, bem como atores do Poder Legislativo, destacando que o Congresso é o local central para o processo de formação de agenda, uma vez que os parlamentares são eleitos para satisfazerem seus eleitores e porque buscam prestígio e diferenciação entre os demais congressistas. Cada um dos participantes e os processos podem atuar como um incentivo ou obstáculo (Kingdon, 2011).

Neste aspecto, cabe ressaltar que, sendo o governo visto como uma organização que possui lógica, capacidades, culturas e procedimentos que influenciam suas decisões, a composição de agendas políticas governamentais sofre influência também de diversos atores que possuem ou não relação direta com o governo. Grupos de interesses, pesquisadores, acadêmicos, consultores e a grande massa representada pela opinião pública, circulam entre os meios políticos internos e externos do governo com grande facilidade, constituindo redes de relacionamento e propondo ideias, 
fazendo lobbies e construindo influências. Mas a existência destes atores não significa ausência de poder por parte dos integrantes do governo. Os ocupantes de cargos públicos possuem autoridade formal garantida pela Constituição e o poder de atuarem como decision-makers oficiais (Flexor, 2010; Kingdon, 2011; Sabatier, 2007).

Kingdon (2011), em seu modelo de "múltiplos fluxos", ressalta que o clima ou temperamento nacional, as forças políticas exercidas pelos grupos de pressão, bem como as mudanças dentro do próprio governo, exercem influência sobre a agenda governamental. Este clima possibilita um ambiente fértil para que algumas ideias possam ser desenvolvidas, o que explica por que algumas questões chegam à agenda, ao passo que outras são descartadas.

Já as forças políticas exercidas pelos grupos de pressão, seja o apoio ou a oposição a uma determinada decisão, sinalizam consenso ou conflito em uma arena política podendo influenciar na tomada de uma determinada decisão. Se há um consenso em torno de uma ideia, os políticos normalmente seguem a onda da maioria. Se há conflito, os políticos pesam as forças favoráveis e desfavoráveis e avaliam para que lado vão, ou pelo menos gostam de saber o que vão enfrentar. Em outras palavras, se há consenso em relação a uma proposta, o ambiente é favorável a mudanças; caso contrário, haverá problemas para determinar-se se um dado item fará ou não parte da agenda.

A questão da formulação do Pronatec está relacionada diretamente a um momento político eleitoral do Brasil que foi a eleição de 2010, onde o tema educação profissional foi colocado de forma evidente em relação às diferentes correntes partidárias. A rigor, já havia por parte do governo um 
desenvolvimento de um conjunto de políticas e ações relacionadas à educação profissional que buscava dar continuidade e aprofundar um processo, iniciado em 2005, de expansão da oferta de educação profissional que não poderia depender apenas da expansão da rede federal, além do fato de experiências negativas com programas de qualificação profissionais anteriores que não alcançaram êxito por serem pulverizadas e de qualidade duvidosa.

O país passava por um momento de crescimento econômico. Determinados setores econômicos acusavam escassez de força de trabalho com as qualificações requeridas em suas respectivas atividades. Algumas empresas declaravam a necessidade de importar trabalhadores qualificados como condição para não frear o crescimento econômico, enfrentando a oposição do movimento sindical, em particular de suas principais centrais que viam, nessa possibilidade, a perda dos melhores postos de trabalho para imigrantes estrangeiros (Baltar, 2015; Filho; Porto; Delfino, 2015).

O trâmite do projeto ocorreu de forma rápida. Conforme Cassiolato e Garcia (2014), com relação ao Pronatec, a presidente da República encaminhou à Câmara dos Deputados mensagem com o Projeto de lei (PL) em 28 de abril de 2011. Segundo esses autores, nas comissões, o PL n 1.209 foi ampliado, mas sem sofrer distorções, recebendo, oficialmente 37 emendas. Seu substituto, que resultou do trabalho das comissões permanentes citadas, deixou de ir à votação por diversas sessões devido a variados motivos $e$ devido a ter ultrapassado o prazo de 45 dias, recebeu uma ofensiva do presidente da Câmara no sentido de retirar sua urgência.

Cassiolato e Garcia (2014) destacam que, mesmo trancando a pauta e com um atraso de 67 dias, o PL n 1.209 seguiu em urgência e finalmente foi a plenário, na sessão deliberativa de 31 de agosto de 2011, onde foi 
apresentado o projeto substitutivo consolidado pela Comissão de Educação e Cultura, com as contribuições das demais comissões.

De acordo com o relato de Cassiolato e Garcia (2014), em uma única sessão, datada de 31 de agosto de 201 1, foi aprovada a redação final do $\mathrm{PL} \mathrm{n}^{0} 1.209$, assinada pelo deputado Jorginho Mello (PSDB-SC). Assim, em seis de setembro de 2011, a Mesa Diretora remeteu o PL aprovado ao Senado Federal que, já aprovado na Câmara, foi lido no plenário do Senado em oito de setembro de 2011, onde foi informado que o mesmo teria tramitação em regime de urgência. $O$ PL então recebeu 27 emendas nas diversas comissões por onde tramitou. As 27 emendas foram rejeitadas em bloco.

Três dias após a aprovação, de acordo com Cassiolato e Garcia (2014), a Mesa do Senado Federal remeteu ofício à Câmara dos Deputados comunicando a aprovação sem alterações e revisão do projeto de lei encaminhando-o à sanção presidencial. A presidência da Mesa do Senado Federal encaminhou Mensagem SF $n^{\circ} 266 / 11$ à presidente da República, submetendo à sanção presidencial autógrafos do projeto. A Lei $n^{\circ} 12.513$ foi sancionada em 26 de outubro de 2011. Decorreram assim seis meses desde o dia em que a mensagem saiu do Palácio do Planalto, apresentando o PL do PRONATEC, até a publicação da lei no Diário Oficial.

\subsection{O Programa}

A partir da identificação do baixo nível de escolaridade e baixo nível de qualificação de parcela majoritária dos trabalhadores brasileiros em um momento em que a economia do país demandava crescentes volumes de 
mão de obra especializada, foi instituído, pela Lei 12.513/2011, o Programa Nacional de Acesso ao Sistema de Ensino Técnico e Emprego (Pronatec). Cassiolato e Garcia (2014) relatam que, sendo o problema da falta de mãode-obra especializada reconhecido pelo núcleo dirigente do governo, que por sua vez se mostrava insatisfeito com as dispersas e ineficazes ações de qualificação profissional então produzidas em diversos ministérios, a proposta do programa teve trânsito rápido no processo decisório.

Os objetivos do programa eram: I - expandir, interiorizar e democratizar a oferta de cursos de educação profissional técnica de nível médio presencial e a distância e de cursos e programas de formação inicial e continuada ou qualificação profissional; II - fomentar e apoiar a expansão da rede física de atendimento da educação profissional e tecnológica; III - contribuir para a melhoria da qualidade do ensino médio público, por meio da articulação com a educação profissional; IV - ampliar as oportunidades educacionais dos trabalhadores, por meio do incremento da formação e qualificação profissional; $\vee$ - estimular a difusão de recursos pedagógicos para apoiar a oferta de cursos de educação profissional e tecnológica; VI - estimular a articulação entre a política de educação profissional e tecnológica e as políticas de geração de trabalho, emprego e renda.

Para o cumprimento de seus objetivos, o Programa atuou por meio das seguintes iniciativas: i) Expansão da Rede Federal; ii) Programa Brasil Profissionalizado; iii) Rede e-Tec Brasil; iv) Acordo de Gratuidade com os Serviços Nacionais de Aprendizagem; e v) Bolsa-Formação.

De acordo com a Secretaria de Educação Profissional e Tecnológica (SETEC), no que se refere à oferta, o grande mérito do Pronatec foi conseguir estruturar um extenso sistema de ofertantes, por meio de redes públicas e privadas, que inclui a Rede Federal de Educação, Ciência e Tecnologia (IFETs), os Sistemas 
Nacionais de Aprendizagem (Sistema S), as escolas técnicas estaduais, além de instituições privadas especificamente credenciadas, que são redes que podem ser gerenciadas.

No Pronatec, foram oferecidos cursos gratuitos nas escolas públicas federais, estaduais e municipais, nas unidades de ensino do SENAI, do SENAC, do SENAR e do SENAT, em instituições privadas de ensino superior e de educação profissional técnica de nível médio. Foram três tipos de curso: Técnico para quem concluiu o ensino médio, com duração mínima de um ano; Técnico para quem está matriculado no ensino médio, com duração mínima de um ano; Formação Inicial e Continuada ou qualificação profissional, para trabalhadores, estudantes de ensino médio e beneficiários de programas federais de transferência de renda, com duração mínima de dois meses.

O Pronatec atendeu prioritariamente: I - estudantes do ensino médio da rede pública, inclusive da educação de jovens e adultos; II - trabalhadores; III beneficiários dos programas federais de transferência de renda; e IV estudantes que tenham cursado o ensino médio completo em escolas da rede pública ou em instituições privadas na condição de bolsista integral, nos termos do regulamento.

O programa se subdividia em treze eixos tecnológicos, a saber: Ambiente e Saúde, Controle e Processos Industriais, Desenvolvimento Educacional e Social, Gestão e Negócios, Informação e Comunicação, Infraestrutura, Militar, Produção Alimentícia, Produção Cultural e Design, Produção Industrial, Recursos Naturais, Segurança e Turismo, Hospitalidade e Lazer.

\subsection{Pronatec - Iniciativas}


O Pronatec envolveu um conjunto de iniciativas. Fizeram parte dele:

- Expansão da Rede Federal: ampliação da oferta de cursos de formação inicial e continuada, técnicos, superiores de tecnologia, licenciaturas e programas de pós-graduação.

- Programa Brasil Profissionalizado: estímulo à ampliação da oferta e ao fortalecimento da educação profissional e tecnológica integrada ao ensino médio nas redes estaduais, em parceria com o Governo Federal.

- Rede e-TecBrasil: oferta de cursos técnicos e de formação inicial e continuada ou de qualificação profissional, na modalidade a distância, com possibilidade de oferecer cursos a distância para instituições da Rede Federal de Educação Profissional, Científica e Tecnológica; as unidades de ensino dos serviços nacionais de aprendizagem (SENAl, SENAC, SENAR e SENAT); e instituições de educação profissional vinculadas aos sistemas estaduais de ensino.

- Acordo de Gratuidade com os Serviços Nacionais de Aprendizagem: ampliação progressiva e aplicação dos recursos do SENAI, do SENAC, do SESC e do SESI, recebidos da contribuição compulsória, em cursos técnicos e de formação inicial e continuada ou de qualificação profissional, em vagas gratuitas destinadas a pessoas de baixa renda, com prioridade para estudantes e trabalhadores.

- FIES Técnico e Empresa: financiamento de cursos técnicos e cursos de formação inicial e continuada ou de qualificação profissional para estudantes e trabalhadores em escolas técnicas privadas e nos serviços nacionais de aprendizagem - SENAI, SENAC, SENAT e SENAR. No FIES Empresa serão financiados cursos de formação inicial e continuada para trabalhadores, inclusive no local de trabalho. 
- Bolsa-Formação: oferta gratuita de cursos técnicos para quem concluiu o Ensino Médio e para estudantes matriculados no Ensino Médio e cursos de formação inicial e continuada ou qualificação profissional.

\subsection{Estruturação}

A SETEC respondia pela estruturação e coordenação de uma extensa rede formada por instituições ofertantes (Rede Federal de Educação Profissional e Tecnológica; Redes Estaduais de Educação; Instituições do Sistema S; Redes Privadas de Educação, no caso do FIES Técnico) e órgãos demandantes de cursos (Ministérios, Estados, Secretarias Estaduais de Governo, entre outros). Ela conta com três Diretorias, cujas competências estão estabelecidas no Anexo I do Decreto $n^{\circ} 7.690 / 2012$, art. 14 a 16.

A criação do Conselho Deliberativo de Formação e Qualificação Profissional foi proposta pela Lei de criação do Pronatec a fim de fortalecer o programa e garantir a coordenação de suas iniciativas com outras ações do governo federal. Esse Conselho é composto por todos os ministérios signatários da lei que instituiu o Programa e do Fórum Nacional de Apoio à Formação e Qualificação Profissional. Seu objetivo é a promoção da articulação e da avaliação dos programas voltados à formação e qualificação profissional no âmbito da administração pública federal (regulamentado pelo Decreto $n^{\circ} 7$. 855/2012).

O Conselho Deliberativo de Formação e Qualificação Profissional contava ainda com um Fórum, instituído pela Portaria MEC n 471, de 03 de junho de 2013, que tem por finalidade subsidiar a atuação do Conselho Deliberativo no cumprimento de suas competências e estimular a instituição de fóruns 
estaduais e distrital de apoio à formação e qualificação profissional. Além desses, ainda temos vários outros Conselhos que fazem interação com o Pronatec, como o Conselho Nacional das Instituições da Rede Federal de Educação Profissional, Científica e Tecnológica (CONIF), Conselho Nacional de Educação (CNE), Conselho Nacional de Dirigentes das Escolas Técnicas vinculadas às Universidades Federais (CONDETUF), entre outros.

\section{Considerações finais}

Face às crescentes desigualdades sociais existentes no país, tem-se a urgência na busca por políticas que busquem reverter esse cenário. É necessário prover condições para que haja não apenas geração de empregos e para que os indivíduos estejam qualificados para competir no mercado de trabalho, como também para que eles possam participar em situação de igualdade da vida política, econômica e social podendo, assim, colher os frutos dessa participação.

É notório que a educação é considerada um importante instrumento para reduzir as desigualdades. O investimento público em educação tende a aumentar a produtividade do trabalho dos mais necessitados, ampliando sua renda, ao mesmo tempo em que reduz o diferencial de rendimento do trabalho pelo efeito da expansão da oferta de trabalho qualificado. Por essas e outras razões, é considerado que a educação é uma das melhores iniciativas para diminuir as desigualdades ao trazer oportunidades de melhor qualificação do conjunto da população.

Os cursos profissionalizantes, em sua maioria, tendem a formar fundamentalmente para atender a demandas específicas do mercado de 
trabalho. Conforme abordado ao longo do artigo, a LDB, em seu artigo 39, estabelece que a educação profissional deve conduzir o cidadão ao permanente desenvolvimento de suas aptidões para a vida produtiva.

O processo de tramitação congressual do Projeto de Lei do programa, conforme relato apresentado por Cassiolato e Garcia (2014), apresentado neste estudo, mostrou que, além de ter encontrado um clima favorável na opinião pública e nas casas legislativas, os dirigentes e gestores do MEC/SETEC contavam com o interesse dos governos estaduais, de prefeitos de cidades importantes e seus representantes, possibilitando um ambiente fértil para que algumas ideias pudessem ser desenvolvidas, o que explica por que algumas questões chegam à agenda, ao passo que outras são descartadas.

Apesar das críticas, o Pronatec se destacou como um elemento estratégico para a construção da cidadania e para uma melhor inserção de jovens e trabalhadores na sociedade na medida em que: fomentou e apoiou a expansão da rede física de atendimento da educação profissional e tecnológica; ampliou e diversificou a oferta de educação profissional e tecnológica gratuita no país; integrou programas, projetos e ações de formação profissional e tecnológica e; democratizou as formas de acesso à educação profissional e tecnológica para públicos diversos.

O Brasil dificilmente conseguirá decolar, rumo ao tão sonhado desenvolvimento, sem antes investir pesadamente na educação. Políticas de educação são políticas de longo prazo, ou seja, só renderão frutos ao final de dez ou quinze anos. Ao longo de nossa história, pouco se fez, em termos práticos, com relação à implementação de uma sólida política de educação que atenda não aos interesses da classe dominante, e sim aos 
interesses da sociedade e que vise à formação do indivíduo. Na verdade, o pouco que se fez, em muitos casos, vem se degradando, ano após ano, com visíveis declínios, tanto na seleção de professores, como nos investimentos em pesquisa e extensão e isto com reflexos diretos na formação de profissionais. Conforme Azevedo et al (2012, p.35), "em síntese, o Brasil tem sido dominado por uma classe burguesa que se mescla com partidos políticos e chega ao governo, e mesmo alardeando que está compromissada com outras ideologias reproduz as mesmas ações de quem estava no poder".

Data da submissão: $31 / 07 / 2019$

Data do aceite: $23 / 01 / 2020$ 


\section{Referências}

Allison, G; Zelikow, P. (1999). Essence of Decision: Explaining the Cuban Missile Crisis. 2. ed. New York: Longman.

Baltar, P. (2015). Crescimento da economia e mercado de trabalho no Brasil. Texto para discussão - IPEA, Brasilia, v. 2036, 2015.

BRASIL (1996). Lei n ${ }^{\circ}$ 9.394, de 20 de dezembro de 1996. Estabelece as diretrizes e bases da educação nacional. Diário Oficial [da] República Federativa do Brasil, Brasília, DF. Disponível em: http://www.planalto.gov.br/ccivil 03/leis/19394.htm. Acesso em: 22 nov. 2017.

BRASIL. (2011). Lei no 12.513, de 26 de outubro de 2011 . Institui o Programa Nacional de Acesso ao Ensino Técnico e Emprego (Pronatec); altera as Leis no 7.998, de 11 de janeiro de 1990, que regula o Programa do SeguroDesemprego, o Abono Salarial e institui o Fundo de Amparo ao Trabalhador (FAT), no 8.212, de 24 de julho de 1991, que dispõe sobre a organização da Seguridade Social e institui Plano de Custeio, no 10.260, de 12 de julho de 2001, que dispõe sobre o Fundo de Financiamento ao Estudante do Ensino Superior, e no 11.129, de 30 de junho de 2005, que institui o Programa Nacional de Inclusão de Jovens (ProJovem); e dá outras providências .Brasília. Disponível em:

http://www.planalto.gov.br/ccivil 03/ato2011-2014/2011/lei/l12513.htm.

Acesso em: 22 nov. 2017.

Boito, A. JR. (2012). Governos Lula: a nova burguesia nacional no poder. In: Boito Jr \& Galvão, A. Política e classes sociais no Brasil dos anos 2000. São Paulo: Alameda

Cassiolato, M. M. C., \& Garcia, R C. (2014). PRONATEC: Múltiplos arranjos e ações para ampliar o acesso à Educação Profissional. Rio de Janeiro: IPEA. Texto para discussão 1919

Ciavatta, M. (2002). A construção da Democracia pós-ditadura militar. Políticas e planos educacionais no Brasil. In: Fávero, Osmar; Semeraro Giovanni (orgs). Democracia e construção do público no pensamento educacional brasileiro. Petrópolis: Vozes.

CNTE, Confederação Nacional dos Trabalhadores em Educação. (2011). Os riscos do Pronatec para a educação técnica profissional. Revista Retratos da Escola, Brasilia, p. 179-184, 2011.

Constituição da República Federativa do Brasil de 1988 (2003). 13 ed. Rio de Janeiro: DP\&A. 
Fauconnet, P. (1978). Educação e Sociologia - Com um estudo da obra de Durkheim. São Paulo: Melhoramentos.

Filho, F.; Porto, R.; Delfino, D.L. (2015). Pronatec Bolsa-Formação: uma avaliação inicial sobre reinserção no mercado de trabalho formal. Relatório Técnico - SPE, Brasília, DF.

Fischer, f.; Miller, g. J.; Sidney, m. (2007). Handbook of Public Policy Analysis: theory, politics, and methods. Florida: CRC Press.

Flexor, G. (2010). Políticas Públicas, atores e regras: uma perspectiva neoinstitucionalista da dinâmica do Programa Nacional de Produção e Uso de Biodiesel. Desenvolvimento em Debate, v. 1, n. maio-agosto, p. 2445.

Frigotto, G. (2005). A política de educação profissional no governo Lula: um percurso histórico controvertido. Educ. Soc., Campinas, vol. 26, n. 92, 10871113, Especial - Out.

Gelinski, C. R. O; Seibel, E. (2008). Formulação de Políticas Públicas: Questões Metodológicas Relevantes. Revista de Ciências Humanas, v. 42, n. 1, p. 227-240.

Gomes, A. V. A. (2016). Que podemos dizer sobre o Pronatec. Consultoria Legislativa, Brasília, p. 1-39.

Gomes, H. S. (2013). Os modos de organização e produção do trabalho e a educação profissional no Brasil. In: BATISTA, E. L; MÜLLER, M. T. (Eds.). A educação profissional n o Brasil. Campinas, São Paulo: Alínea, p. 286.

Gomes, R. C. (2004). Who are the relevant stakeholders to the local government context? Empirical evidences on environmental influences in the decision-making process of english local authorities. Brazilian Administration Review, v. 1, n. March, p. 34-52.

Gramsci, A. (2000). Cadernos do cárcere. Volumes 1 e 3. Introdução ao estudo da filosofia. A filosofia de Benedetto Croce. Rio de Janeiro: Civilização Brasileira.

Kingdon, J. W. (2011). Agendas, Alternatives ad Public Policies. Boston: Longman.

Kuenzer, A. Z. (2010). As políticas de educação profissional- uma reflexão necessária. In: Educação profissional e tecnológica no Brasil contemporâneo. 01. ed. Porto Alegre: Molls, Jaqueline (org.), pp. 253-270. Lima, M. (2012). Problemas da educação profissional do Governo Dilma: PRONATEC, PNE e DCNEMs. Trabalho \& Educação, Belo Horizonte, v. 21, n. 2, p. 73-91.

Moura, D. H. (2010). Ensino médio e educação profissional. In: Moll, J. (Ed.). Educação profissional e tecnológica no Brasil contemporâneo. Porto Alegre: Artmed, p. 312. 
Neves, L. M. W. (2010). Direita para o social e esquerda para o capital: intelectuais da nova pedagogia da hegemonia no Brasil. São Paulo: Xamã.

Neves. (2000). Por que dois planos nacionais de educação? In: Neves, L.M. (org). Educação e política no limiar do século XXI. Campinas: autores Associados.

Oliveira, D. A. (2009). Regulação e avaliação de políticas públicas educacionais. In: DOURADO, L.F. (org). Políticas e gestão da educação no Brasil. São Paulo: Xamã., 11-30.

Otranto, C.R. (2012). Reforma da Educação Profissional no Brasil: marcos regulatórios e desafios. Revista Educação em Questão, Natal, v. 42, n. 28, p. 199-226, jan./abr.

Rawls, J. (1997). Uma teoria da justiça. São Paulo: Martins Fontes.

Romanelli, O. O. (2005). História da Educação no Brasil. 29ª Ed. Petrópolis, RJ: Vozes.

Rua, M. G. (2000). Estado, Governo e Administração Pública e a questão social brasileira. Brasília: Ministério da Fazenda, Escola de Administração Fazendária - ESAF.

Sabatier, P. A. (2007). Theories of the Policy Process. Colorado, USA: Westview Press.

Saviani, D. (2007). História das ideias pedagógicas no Brasil. Campinas, SP: Autores Associados.

Teodoro, A. (2008). Novos modelos de regulação transnacional de políticas educativas. Evidências e possibilidades. In: Teodoro, António (org.) Tempos e andamentos nas políticas de educação. Estudos ibero-americanos, 1938.

Wittaczik, L.S (2008). Educação Profissional no Brasil: histórico. E-Tech: Atualidades Tecnológicas para Competitividade Industrial, Florianópolis, v. 1, n. 1, 77-86 


\section{Biografia}

Fabiana Carvalho da Silva Bispo

Mestre em Administração Pública e aluna do curso de Doutorado em Administração, ênfase em Administração Pública e Políticas Públicas, da Universidade de Brasília.Docente do Instituto Federal de Brasilia, atuando nos curso Técnico e Tecnológico da área de Gestão e Negócios.

E-mail: fabiana.bispo@ifb.edu.br / ORCID: http://orcid.org/0000-0003-45427668 